Article

\title{
Efficient and Selective Catalytic Conversion of Hemicellulose in Rice Straw by Metal Catalyst under Mild Conditions
}

\author{
Xiaorui Yang, Jing Zhao, Jinhua Liang and Jianliang Zhu * \\ College of Biotechnology and Pharmaceutical Engineering, Nanjing Tech University, 30 South Puzhu Road, \\ Nanjing 211800, China; yangxiaorui@njtech.edu.cn (X.Y.); zhaojing1112@163.com (J.Z.); \\ Jhliang@njtech.edu.cn (J.L.) \\ * Correspondence: jlzhu@njtech.edu.cn
}

Received: 3 December 2020; Accepted: 17 December 2020; Published: 18 December 2020

\begin{abstract}
Rice straw is an abundant material with the potential to be converted into a sustainable energy resource. Transition-metal catalysis activated the $\mathrm{C}-\mathrm{O}$ bond in the hemicellulose of raw rice straw, cleaving it to form monosaccharides. The mechanism of rice straw catalytic conversion had a synergistic effect due to in situ acid catalysis and metal catalysis. The conditions for the hydrogenation of hemicellulose from rice straw were optimized: catalyst to rice straw solid/solid ratio of 3:10, stirring speed of $600 \mathrm{r} / \mathrm{min}$, temperature of $160^{\circ} \mathrm{C}$, time of $3 \mathrm{~h}$, solid/liquid ratio of 1:15, and $\mathrm{H}_{2}$ gas pressure of $1.5 \mathrm{MPa}$. An excellent hemicellulose conversion of $97.3 \%$ with the yields of xylose and arabinose at $53.0 \%$ and $17.3 \%$, respectively, were obtained. The results from FTIR and SEM experiments also confirmed the destruction of the rigidity and reticulate structure of rice straw after the catalytic reaction.
\end{abstract}

Keywords: rice straw; hemicellulose conversion; structure; metal catalysis; $\mathrm{C}-\mathrm{O}$ bond cleavage

\section{Introduction}

With the development of industry and society, the contradiction between the demand for resources and the shortage of non-renewable fossil resources has intensified [1,2]. Furthermore, overutilization of fossil resources has led to severe environmental issues, such as the greenhouse effect and haze [3]. To avert these contradictions, researchers have developed alternatives to replace exhausted fossil resources. Thus, there is a potential for utilizing renewable lignocellulosic biomass as a sustainable energy resource [4,5]. Rice straw (RS) is an abandoned agricultural waste with around 200 million tons produced in China annually. It is a popular lignocellulosic biomass resource and is renewable, programmable, and inedible with a large yield [6]. Recent studies reported the conversion of rice straw into valuable chemicals, especially biomaterials and biofuels; these efforts have attracted interest in recent times $[7,8]$.

Rice straw predominantly contains $32-47 \%$ cellulose (a hexose polymer), $19-27 \%$ hemicellulose (a pentose polymer), and 5-24\% lignin (a phenol polymer) [9]. Hemicellulose represents a relatively large fraction of polysaccharides in the lignocellulosic biomass. However, it gets wasted during the several processes in bio-based industries, such as pulping and bioethanol- and resin-related processes [10,11]. Nevertheless, hemicellulose has numerous excellent properties that could be used in a variety of industries, such as food, medicine, chemicals, fuels, and biomaterials [12-15]. Thus, efficient degradation of hemicellulose has the potential to generate energy, achieving maximum utilization of a renewable resource.

Hemicelluloses are closely associated with cellulose fibrils and are abundant in the primary and secondary layers of the rice straw cell wall. They act as a coat between and around the cellulose fibrils, 
cross-linking with lignin via ester bonds and giving rigidity to the plant tissue [16]. Due to their complex structure, rice straw components have evolved to resist degradation. Few studies reported the hydrolyzation of cellulose or hemicellulose directly from raw material without pretreatment $[17,18]$. Homogeneous and heterogeneous catalysis reactions degrade the rigidity and reticulate structural features of lignocelluloses [19-22]. The homogeneous catalysis technique is not suitable for industrial production; it has several disadvantages, such as high corrosion of the equipment, separation issues, poor recovery and reuse of the catalyst, and high production cost [23-25]. Hence, the researchers favor the heterogeneous catalysis reactions, despite their slower mass transfer and lower productivity; these reactions include solid acid and base catalysis, immobilized enzyme or ionic liquid reaction, and transition-metal catalysis [26-28].

Transition-metal catalysis plays an important role in many catalytic processes in industrial applications [29]. Catalytic hydrogenation using metal oxides is an environment-friendly process for transforming the low-value raw materials to high-value products. The solvent is always water with no addition of chemicals and no wastes discharged [27,30]. Currently, several precious metals are used as catalysts: platinum $(\mathrm{Pt})$, palladium $(\mathrm{Pd})$, ruthenium $(\mathrm{Ru})$, iridium $(\mathrm{Ir})$, and rhodium $(\mathrm{Rh})$ [31-33]. The utilization of cheap and efficient catalysts and catalytic systems is critical to the development of efficient processes for the selective production of sugars from components of raw materials. Thus, non-precious metals are gaining popularity as catalysts for hydrogenation. Several studies have extensively applied copper-based catalysts in hydrogenolysis owing to their high selectivity for $\mathrm{C}-\mathrm{O}$ bond cleavage [32]. However, only a few have reported the hydrogenolysis of raw lignocellulosic biomass catalyzed by non-precious metallic oxides, such as copper oxide $(\mathrm{CuO})$.

Herein, one-step hydrogenolysis of raw material catalyzed by copper oxide as the catalyst was investigated, aiming at the selective conversion of the major components in rice straw, especially hemicellulose, into sugars under mild conditions. X-ray diffraction (XRD) and X-ray photoelectron spectroscopy (XPS) were employed to examine the catalyst. Additionally, Fourier-transform infrared spectroscopy (FTIR) and scanning electron microscopy (SEM) were performed to detect the chemical and structural transformations. This novel process is environmentally clean and generates no waste. The selective cleavage of the $\mathrm{C}-\mathrm{O}$ bond in rice straw, specifically hemicellulose, feasible under mild conditions, represents a promising process for utilizing this abundant resource.

\section{Materials and Methods}

\subsection{Raw Material}

Rice straw (RS) samples were gathered from Nanjing, Jiangsu province, China. They were prewashed under tap water and dried at $60{ }^{\circ} \mathrm{C}$ for $12 \mathrm{~h}$. The dried straw samples were physically pulverized, sieved using a 20-60 mesh (10-62 $\mu \mathrm{m})$ sieve, and sealed in a plastic pocket for subsequent use. The native RS constitution was $37.9 \%$ cellulose, $20.6 \%$ hemicellulose, $19.0 \%$ lignin, $7.4 \%$ ash, and $8.3 \%$ alcohol extract. Chemical reagents were purchased from Sinopharm Chemical Reagent Co. Ltd. (Shanghai, China).

\subsection{Preparation of $\mathrm{CuO}$ Catalyst}

The catalyst was prepared as follows: A copper (II) acetate solution was slowly added to a sodium hydroxide solution, forming a mixture with a 1:2 mole ratio. This mixture was stirred, precipitated, and aged for $2 \mathrm{~h}$. After the precipitates settled and evenly distributed, they were washed to remove any impurities. The resultant was the neutral precipitation solution. This precipitated liquid was stored overnight. Then, it was filtered and dried at $100{ }^{\circ} \mathrm{C}$ for $3 \mathrm{~h}$. The dried, hardened cake was pulverized to the particle size of about $75 \mu \mathrm{m}$ and then calcined at $300^{\circ} \mathrm{C}$ for $3 \mathrm{~h}$, producing the $\mathrm{CuO}$ catalyst. 


\subsection{CuO-Catalyzed Hydrogenation of Hemicellulose in Rice Straw}

The hydrogenation of the RS was performed in an airtight, $250 \mathrm{~mL}$ stainless steel reactor with a $100 \mathrm{~mm}$ diameter, a $150 \mathrm{~mm}$ length, and a $12 \mathrm{~mm}$ thick wall. Single-factor experiment was performed to investigate the effect of the CuO-catalyzed hydrogenation of RS. Initially, RS, catalyst, and water were added into the reactor in a certain proportion, with a catalyst to RS ratio of 1:1-1:5 and a solid to liquid ratio of 1:9-1:17; the reactor was closed; hydrogen $\left(\mathrm{H}_{2}\right)$ gas was passed through the reactor at a certain pressure (1.0 MPa-2.5 MPa); and the contents were stirred at a speed of $600 \mathrm{r} / \mathrm{min}$. The reactor was heated to a target temperature $\left(130-160^{\circ} \mathrm{C}\right)$ for a few hours $(1-5 \mathrm{~h})$. After the incubation, the reactor was quenched in cold water. The two controls included hydrogenation of RS without catalyst or hydrogen under the same incubation conditions. The hydrolyzates were filtered and washed with tap water, the catalyst solutions were recovered, and the samples were dried at $60{ }^{\circ} \mathrm{C}$ before weighing and analysis. The supernatant fractions were collected for analysis of sugars using high performance liquid chromatography (HPLC). The reaction process under each condition was performed twice.

\subsection{Catalyst Recovery and Recycle Experiment}

After the hydrogenation and filtration steps, the hydrolyzate slurries consisted of the residual RS and catalyst. These slurries were suspended in water and stirred for a few minutes to ensure the complete dispersion of RS residues and catalysts in water. This slurry was then filtered with a screen mesh to separate the catalysts from the residues. This process was repeated to ensure good recovery of the catalyst. Repeated cycles of RS hydrogenation followed by the catalyst recovery were performed to investigate the recyclability of catalyst, and all tests were carried out under the optimal conditions as single-factor experiments were performed.

\subsection{Compositional Analysis and Characterization of Rice Straw and Treated Hydrolyzates}

The composition of the rice straw samples was determined according to the standard National Renewable Energy Laboratory (NREL) analytical procedures, including acid hydrolysis, HPLC analysis, and gravimetric analysis [34]. The hydrolyzate slurry was filtered, and the filtrate fractions were analyzed through HPLC, equipped with a differential refractive index detector and an automatic injector.

The sugar contents in the hydrolyzates were detected by HPLC, equipped with an Aminex HPX-87H analytical column ( $300 \mathrm{~mm} \times 7.8 \mathrm{~mm}$, Bio-Rad, Hercules, CA, USA). The following conditions were used: $20 \mu \mathrm{L}$ injection volume, $0.6 \mathrm{~mL} / \mathrm{min}$ flow rate, water as mobile phase, RID-10A differential refractive detector, $50{ }^{\circ} \mathrm{C}$ column temperature, and $60 \mathrm{~min}$ residence time. Prior to HPLC injection, all samples were filtered through a $0.45 \mu \mathrm{m}$ membrane. The individual monosaccharide contents were calculated using their respective calibration curves prepared using known standards. The relevant values were calculated as Equations (1)-(7):

$$
\begin{gathered}
\text { Hemicellulose conversion }(\%)=\frac{(\text { Weight of hemicellulose in RS }(\mathrm{g}) \text {-Weight of hemicellulose in residue }(\mathrm{g})) \times 100}{\text { Weight of hemicellulose in RS }(\mathrm{g})} \\
\text { Cellulose conversion }(\%)=\frac{(\text { Weight of cellulose in RS }(\mathrm{g}) \text {-Weight of cellulose in residue }(\mathrm{g})) \times 100}{\text { Weight of cellulose in RS }(\mathrm{g})} \\
\text { RS conversion }(\%)=\frac{\text { Weight of RS }(\mathrm{g})-\text { Weight of residue }(\mathrm{g})}{\text { Weight of RS }(\mathrm{g})} \times 100 \\
\text { Lignin removal }(\%)=\frac{\text { Weight of lignin in RS }(\mathrm{g})-\text { Weight of lignin in residue }(\mathrm{g})}{\text { Weight of lignin in RS }(\mathrm{g})} \times 100 \\
\text { Xyloxe yield }(\%)=\frac{\text { Weight of xylose }(\mathrm{g})}{\text { Weight of hemicellulose in RS }(\mathrm{g})} \times 100 \\
\text { Arabinose yield }(\%)=\frac{\text { Weight of arobinose }(\mathrm{g})}{\text { Weight of hemicellulose in RS }(\mathrm{g})} \times 100
\end{gathered}
$$




$$
\text { Glucose yield }(\%)=\frac{\text { Weight of glucose }(\mathrm{g})}{\text { Weight of cellulose in RS }(\mathrm{g})} \times 100
$$

\subsection{Characterization of Catalyst and Rice Straw Samples}

The crystallinity of the samples was analyzed using X-ray diffraction (XRD) (Rigaku Smartlab, Tokyo, Japan), in conjunction with a $\mathrm{Cu} K \alpha$ radiation source $(\lambda=0.1542 \mathrm{~nm})$ operated at $40 \mathrm{kV}$ and $100 \mathrm{~mA}$. X-ray photoelectron spectroscopy (XPS) was carried out on a Thermo Scientific K-Alpha spectrometer equipped with an $\mathrm{Al} \mathrm{Ka} \mathrm{X-ray} \mathrm{radiation} \mathrm{source} \mathrm{(} \mathrm{h} v=1486.6 \mathrm{eV}, 12 \mathrm{Kv}, 6 \mathrm{~mA})$. The binding energies were calibrated using the $\mathrm{C} 1 \mathrm{~s}$ peak at $284.5 \mathrm{eV}$ as the reference. Fourier-transform infrared spectroscopy (FTIR) (ALPHA-Bruker, Bruker, Karlsruhe, Germany) was performed to detect the changes in functional groups in the RS samples due to hydrogenation. The FTIR spectra of samples were recorded in the range of 4000-400 $\mathrm{cm}^{-1}$. The microphysical features of the surfaces and energy spectra of the samples were examined by scanning electron microscopy (SEM) (JSM-6510, JEOL, Tokyo, Japan) and energy spectrometer (Noran7, Thermo, Waltham, MA, USA), respectively. Prior to scanning, the specimens were mounted with carbon-coated conductive tape on the pin-mount specimen holders and coated with gold for approximately $20 \mathrm{~min}$. The images were captured at an acceleration of $15 \mathrm{kV}$ voltage.

\section{Results and Discussion}

Hydrogenation technology has been applied to utilize raw rice straw (RS) as a sustainable resource due to its unique advantages. However, the relevant research in this field is scanty. In the following sections, we exhibit the results of our investigation of copper oxide $(\mathrm{CuO})$-catalyzed hydrogenation of rice straw leading to hemicellulose conversion.

\subsection{Factors Affecting Hemicellulose Conversion Catalyzed by $\mathrm{CuO}$ from Rice Straw}

The effect of catalysts is of particular importance as catalysts drive the hydrogenation reaction. The amount of catalyst added and the transport process of catalyst and raw material in the medium influence the effective contact between the catalyst and the material. Figure 1a illustrates the effect of catalyst-to-rice straw solid/solid ratio (1:1 to 1:5) on hemicellulose conversion with the other conditions remaining constant $\left(\mathrm{H}_{2}\right.$ pressure of $1.5 \mathrm{MPa}$, stirring speed of $600 \mathrm{r} / \mathrm{min}$, temperature of $160{ }^{\circ} \mathrm{C}$, time of $3 \mathrm{~h}$, and solid/liquid ratio of 1:15). The xylose and arabinose yields increased with an increase in the amount of catalyst used. The optimal solid/solid ratio was 3:10, beyond which the yields decreased.

In the initial stage of hydrogenation of the rice straw, the $\mathrm{CuO}$ catalyst reduced to form active copper, which then adsorbed on the surface of the RS. The catalyst first encountered the waxy coating and the hemicellulose in the outer layers of the RS, followed by the inner layers. A higher catalyst dosage ratio translates to more RS components encountered by the catalyst with more catalyst embedding in the hemicellulose, converting it into the desired products. Thus, the extent of contact between the catalyst and the hemicellulose in RS is the limiting factor in hemicellulose hydrogenation. Besides, the reaction is heterogeneous, relying on the efficacy of solid-to-solid transfer. After its hydrogenation, the macromolecular structure of the RS collapsed. Besides, copper oxide, a non-precious metal oxide catalyst, is cheaper than a precious metal catalyst and will be widely used in industry.

Unlike the organic acids and ionic liquids, the water did not effectively dissolve the RS, thus preventing optimal contact between the catalyst and the reactant [35]. Since the RS hydrogenation was a heterogeneous catalytic reaction, there was a reduced collision between the reactant and the catalyst, making the reaction process and its mechanism more complex. Therefore, we investigated the effect of solid/liquid ratio (1:9-1:17) on hemicellulose conversion in RS under similar conditions $\left(\mathrm{H}_{2}\right.$ pressure of $1.5 \mathrm{MPa}$, stirring speed of $600 \mathrm{r} / \mathrm{min}$, temperature of $160^{\circ} \mathrm{C}$, solid/solid ratio of 3:10, and time of $3 \mathrm{~h}$ ). The xylose and arabinose yields were the highest with a solid/liquid ratio of 1:15 (Figure 1b). Thus, a larger volume of the liquid medium could increase its flow and the mass transfer, 
increasing the interaction between the catalyst and RS, which favors the hydrogenation conversion of hemicellulose.
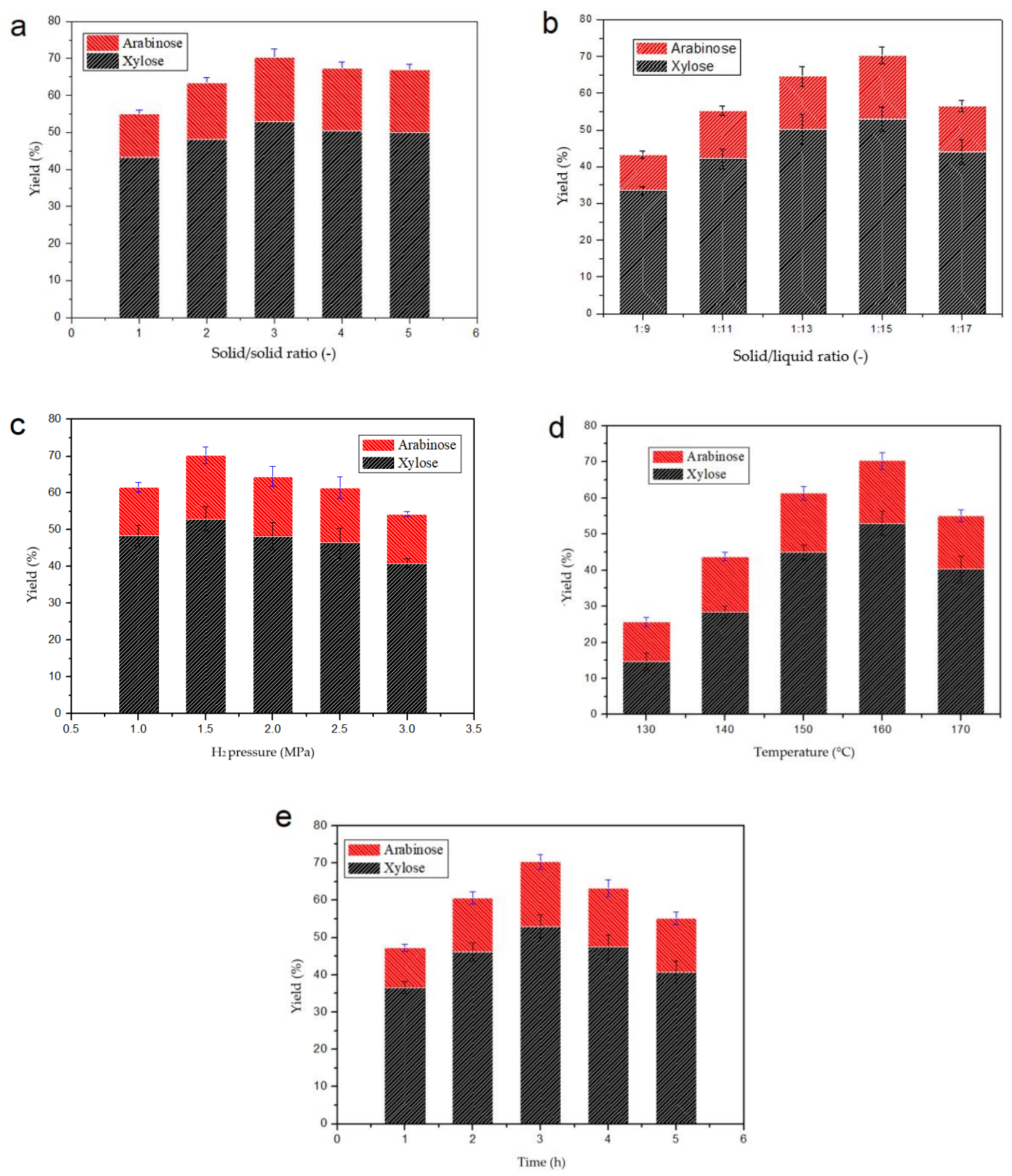

Figure 1. Effect of factors on hemicellulose conversion from rice straw (RS). (a): Solid/solid ratio (-); (b): Solid/liquid ratio (-); (c): $\mathrm{H}_{2}$ pressure (MPa); (d): Temperature $\left({ }^{\circ} \mathrm{C}\right)$; (e): Time (h).

As the water was the only solvent in the reaction, the reactants and products had opposing solubility in water; the RS was hydrophobic and insoluble in water, whereas the monosaccharides were hydrophilic small molecules and readily soluble. Thus, the products dissolved in water might promote higher yields. They also easily separated from the raw material, which was good for the subsequent steps of the process. Nevertheless, the addition of water does not always facilitate the reaction, as seen in the yields for samples with a 1:17 ratio.

We used hydrogen $\left(\mathrm{H}_{2}\right)$ gas to reduce the $\mathrm{CuO}$ catalyst for the hydrogenation reaction. We investigated the effect of $\mathrm{H}_{2}$ gas pressure (1.0-2.5 MPa) on the hemicellulose conversion from 
RS with other conditions remaining unchanged (solid/solid ratio of 3:10, stirring speed of $600 \mathrm{r} / \mathrm{min}$, temperature of $160{ }^{\circ} \mathrm{C}$, time of $3 \mathrm{~h}$, and solid/liquid ratio of 1:15). Figure $1 \mathrm{c}$ displays the data on the effect of $\mathrm{H}_{2}$ gas pressure on hemicellulose conversion from RS. The xylose and arabinose yields enhanced marginally with an increase in $\mathrm{H}_{2}$ gas pressure from 1.0 to $1.5 \mathrm{MPa}$. The yields declined as the pressure continued to increase from 1.5 to $2.5 \mathrm{MPa}$, suggesting that $1.5 \mathrm{MPa}$ is the optimal $\mathrm{H}_{2}$ gas pressure.

Under the $\mathrm{H}_{2}$ gas pressure of $1.5 \mathrm{MPa}, \mathrm{H}_{2}$ gas readily reduced $\mathrm{CuO}$ to active $\mathrm{Cu}$, thus effectively catalyzing the hemicellulose conversion. The reaction system contained all three states of matter: gas, liquid, and solid. This made the reaction more reliable on the mass transfer; therefore, more hydrogen would benefit for the reaction. However, $\mathrm{H}_{2}$ gas pressure higher than $1.5 \mathrm{MPa}$ promoted hydrogenation of the monosaccharides into alcohols. Additionally, higher pressure requires a larger and stronger reactor, thus increasing the cost of the process.

Figure $1 \mathrm{~d}$ displays the effect of temperature $\left(130-160^{\circ} \mathrm{C}\right)$ on hemicellulose conversion in RS depicted as the plot of yields of xylose and arabinose versus temperature. Notably, for the samples with a solid/solid ratio of 3:10, solid/liquid ratio of 1:15, and incubation of $3 \mathrm{~h}$, the yields of both xylose and arabinose severely increased with an increase in temperature from 130 to $160{ }^{\circ} \mathrm{C}$. The highest yield for xylose and arabinose at $160^{\circ} \mathrm{C}$ was $53.0 \%$ and $17.3 \%$, respectively. At higher temperatures, the yields for both declined. This might be due to the further conversion of pentoses into byproducts (e.g., furfural), intermediate products, and related alcohols (data not shown). Our results are in agreement with the results of Zhong et al. [24]. They designed selective hydrolysis of hemicellulose from wheat straw using a solid acid $\mathrm{SO}_{4}{ }^{2-} / \mathrm{Fe}_{2} \mathrm{O}_{3}$ catalyst. Under their optimal conditions, the maximum combined yield of xylose and arabinose was $63.5 \%$, less than our combined yield of $70.3 \%$.

The $\mathrm{CuO}$ catalyst reduced and transformed to active $\mathrm{Cu}^{0}$ at high temperature in $\mathrm{H}_{2}$ atmosphere; the more active $\mathrm{Cu}^{0}$ in the catalyst, the higher will be the xylose and the arabinose yields. The elevated temperatures provided more energy required for the catalysis of RS. The active $\mathrm{Cu}^{0}$ was employed for the hydrocracking of the long-chain macromolecules in hemicellulose into low-molecular-weight monosaccharides. These monosaccharides might further convert into other non-sugars in the acidic condition.

Hot water in the hydrogenation reaction was used as a solvent medium. It also acted as an $\mathrm{H}^{+}$ donor during the in situ-generated acid transfusion and autocatalyzed the hydrolysis of hemicellulose, thus altering the lignin structure [36]. However, hot water is not always a positive aspect, as it could also result in unwanted byproducts.

Considering the reduction in the process and reaction energy consumption, we investigated the effect of reaction time (1-5 h) on hemicellulose conversion in RS under the described reaction conditions $\left(\mathrm{H}_{2}\right.$ pressure of $1.5 \mathrm{MPa}$, stirring speed of $600 \mathrm{r} / \mathrm{min}$, temperature of $160^{\circ} \mathrm{C}$, solid/solid ratio of 3:10, and solid/liquid ratio of 1:15). Figure 1e illustrates the effect of various reaction times. The xylose and arabinose yields were the highest at a reaction time of $3 \mathrm{~h}$. However, the yields declined markedly with the prolonged reaction time of $5 \mathrm{~h}$.

We hypothesize that the hydrogenated products of hemicellulose conversion in RS further decomposed into smaller molecules under the high temperature as time prolonged. This continued decomposition into unwanted byproducts could be a result of the in situ acetic acid (data not shown).

\subsection{Recycling of Catalyst}

The $\mathrm{CuO}$ catalyst prepared was examined for 5 recycle times listed in Table 1 . We can see from Table 1 the xylose and arabinose both declined along with the recycle time increases, from $70.3 \%$ to $65.7 \%$, indicating that no significant activity loss occurred in catalyst during the recycling process. Obviously, this merit will promote the industrial application of $\mathrm{CuO}$ catalyst in the exploiting of lignocellulosic biomass resources. It is also worth noting that the mass loss of catalyst during recycling could not be ignored, and the feeding might accordingly change in every recycle during the test. 


\subsection{Controlled Trial}

Aiming to verify the effects of copper oxide as catalyst on hemicellulose conversion in rice straw and to reveal the mechanism of the $\mathrm{CuO}$ catalytic reaction, the products, under the conditions of solid/solid ratio of 3:10, stirring speed $600 \mathrm{r} / \mathrm{min}$, temperature of $160^{\circ} \mathrm{C}$, time of $3 \mathrm{~h}$, solid/liquid ratio of $1: 15$, and $\mathrm{H}_{2}$ pressure of $1.5 \mathrm{MPa}$ (HRS) in the slurry and solid residues, were assessed comparing with control trials: untreated rice straw (URS), similar condition with HRS without catalyst (LHW), and similar condition with HRS without $\mathrm{H}_{2}$ (LHC). Table 2 summarizes these results.

Table 1. Effect of catalyst recycle time on hemicellulose conversion from RS.

\begin{tabular}{cccc}
\hline Recycle Time & $\begin{array}{c}\text { Mass of Catalyst } \\
\text { (g) }\end{array}$ & $\begin{array}{c}\text { Mass of RS } \\
\text { (g) }\end{array}$ & $\begin{array}{c}\text { Yield of Xylose and Arabinose } \\
(\mathbf{\%})\end{array}$ \\
\hline 0 & 3.000 & 10.000 & 70.3 \\
\hline 1 & 2.320 & 7.733 & 69.7 \\
\hline 2 & 2.243 & 7.477 & 69.0 \\
\hline 3 & 2.165 & 7.217 & 68.1 \\
\hline 4 & 2.087 & 6.957 & 66.6 \\
\hline 5 & 2.003 & 6.677 & 65.7 \\
\hline
\end{tabular}

Table 2. Comparison of the slurry and solid residue of URS, LHW, LHC, and HRS.

\begin{tabular}{|c|c|c|c|c|c|c|c|c|c|c|c|}
\hline & $\mathrm{pH}$ & $\begin{array}{l}\text { Glucose } \\
\text { Yield } \\
(\%)\end{array}$ & $\begin{array}{c}\text { Xylose } \\
\text { Yield } \\
(\%)\end{array}$ & $\begin{array}{l}\text { Arabinose } \\
\text { Yield } \\
(\%)\end{array}$ & $\begin{array}{c}\text { Cellulose } \\
(\%)\end{array}$ & $\begin{array}{l}\text { Hemicellulose } \\
\text { (\%) }\end{array}$ & $\begin{array}{l}\text { Lignin } \\
(\%)\end{array}$ & $\begin{array}{c}\mathrm{RS} \\
\text { Conversion } \\
(\%)\end{array}$ & $\begin{array}{c}\text { Cellulose } \\
\text { Conversion } \\
(\%)\end{array}$ & $\begin{array}{c}\text { Hemicellulose } \\
\text { Conversion } \\
(\%)\end{array}$ & $\begin{array}{c}\text { Lignin } \\
\text { Removal } \\
(\%)\end{array}$ \\
\hline URS & - & - & - & - & 37.8 & 20.5 & 19.0 & - & - & - & - \\
\hline LHW & 3.9 & 1.2 & 18.5 & 7.7 & 46.7 & 12.2 & 19.9 & 26.6 & 9.4 & 56.2 & 23.0 \\
\hline LHC & 3.9 & 1.2 & 22.7 & 8.7 & 48.0 & 12.1 & 23.1 & 28.9 & 9.8 & 57.8 & 13.4 \\
\hline HRS & 3.9 & 15.5 & 53.0 & 17.3 & 43.4 & 1.1 & 23.3 & 50.2 & 42.9 & 97.3 & 38.8 \\
\hline
\end{tabular}

We observed that the catalyst preferentially acted on hemicellulose than cellulose as shown in Table 2. About $97.30 \%$ of hemicellulose converted into the low-molecular-weight molecules in HRS with only $1.11 \%$ hemicellulose remaining in the RS residue. This suggested that the catalysis resulted in highly efficient degradation of hemicellulose, similar to the results of Hou et al. [37]. In their study, the hemicelluloses degraded drastically with only $1.5 \%$ remaining in the residue after treatment with choline chloride/oxalic acid at $120^{\circ} \mathrm{C}$ for $4 \mathrm{~h}$. Our results are also similar to those of the research of Kapoor et al. [38], in which the dilute acid selectively degraded hemicelluloses from native RS, at an acid concentration of $0.65 \mathrm{wt} \%$ and a temperature of $157^{\circ} \mathrm{C}$; the left over total xylan and arabinan were $3.4 \%$.

Moreover, the cellulose conversion in our study was $42.9 \%$, and the cellulose content increased to $43.4 \%$ compared with the URS. The possible reason for this finding could be the efficient hemicellulose conversion and partial delignification $(38.8 \%)$. These might have, consequently, loosened the firm structural linkages between hemicellulose and lignin, causing partial exposure of cellulose, depolymerizing the cellulose to oligosaccharides or low-chain sugars. However, the glucose yield was only $15.5 \%$. This indicates that the cellulose in RS mostly degraded into oligosaccharides or low-molecular glucan. This, in turn, led to the robust crystalline structure of cellulose arresting further degradation, which may require severe conditions.

The combined yield of xylose and arabinose in HRS in the presence of the $\mathrm{CuO}$ catalyst was much higher $(44.2 \%)$ than that in the LHW control in the absence of the catalyst, reflecting the exceptional effect of the $\mathrm{CuO}$ catalyst on hemicellulose conversion. Similarly, the combined yield of xylose and arabinose in HRS was higher compared to that in the LHC control. The presence of $\mathrm{H}_{2}$ gas reduced the $\mathrm{CuO}$, which then acted as the catalyst for the cleavage of $\mathrm{C}-\mathrm{O}$ bonds. The individual yields of xylose and arabinose were only $22.7 \%$ and $8.7 \%$, respectively, in the absence of $\mathrm{H}_{2}$ gas in LHC, despite the 
presence of the $\mathrm{CuO}$ catalyst. These results helped decipher the mechanism in the CuO-catalyzed RS degradation. $\mathrm{CuO}$, as a metal oxide, has less stability in water. Our results were similar to those by $\mathrm{Li}$ et al. [39]. Our results of the $\mathrm{pH}$, the yields of xylose and glucose, and the extent of lignin removal were similar to their results and similar to those with liquid hot water pretreatment. They assumed that $\mathrm{CuO}$ could not react with the weak acids released during pretreatment and had no effect on recovery and degradation of xylose. The conversion of RS in HRS was higher than 50\%, or the sum of hemicellulose, cellulose, and lignin conversion of RS might also be a result of dissolution of most of the extractives in RS during degradation, including aliphatic acids, phenolic glycosides, and inorganic ions [40].

The slurry of HRS was acidic, and its $\mathrm{pH}$ was similar to that of the LHW control, the equivalent of liquid hot water treatment. The reaction is similar as water is the sole solvent. The intermolecular hydrogen bonds in solvent water decompose into hydrogen free radicals or protons $\left(\mathrm{H}^{+}\right)$under high temperature and pressure conditions [35]. These protons promoted the cleavage of ester bonds of acetyl side-chains of hemicellulose, resulting in the formation of acetic acid. Subsequently, the reactive $\mathrm{H}^{+}$would hydrocrack the long-chain hemicellulose in RS into low-molecular-weight fragments. Furthermore, $\mathrm{H}^{+}$effectively stabilized the free radicals produced from the decomposition of RS at high temperature, preventing further degradation of the low-molecular-weight fragments. After the final steps of the reaction, the slurry was acidic, with a $\mathrm{pH}$ value of 3.9. Li et al. [39] reported that $\mathrm{CuO}$ hardly reacted with the weak acids released during the degradation of hemicellulose and monosaccharides, which was consistent with our LHC treatment results (Table 2). We suspect that the hemicellulose conversion is a result of the synergistic effects of the transition metal catalyst and the liquid hot water treatment.

\subsection{Reaction Mechanism of Hemicellulose Conversion from Rice Straw}

Copper oxide was employed to catalyze the hemicellulose conversion in RS. The previous experiment proved that the conversion of hemicellulose in RS is feasible and effective at a low partial pressure of $\mathrm{H}_{2}$ gas. The mechanism of hemicellulose conversion in $\mathrm{RS}$ catalyzed by $\mathrm{CuO}$ might be the synergistic effect of in situ acid catalytic conversion and metal catalysis, but the synergistic effect of liquid hot water was not always a positive aspect, as liquid hot water hydrolyzed hemicellulose and resulted in unwanted by-products. We propose that $\mathrm{CuO}$ catalyzes the cleavage of $\mathrm{C}-\mathrm{O}$ bond to generate monosaccharides and other low-molecular-weight oligosaccharides.

Transition-metal catalysts play an important role in catalytic reactions as most chemical processes utilize catalysts. We prepared the $\mathrm{CuO}$ catalyst and then reduced it to $\mathrm{Cu}^{0}$ under $\mathrm{H}_{2}$ gas atmosphere based on the equation of hydro-reduction of copper oxide. Hydrogen gas is a reducing agent and reacts with copper oxide to form copper and water under heating conditions. This reaction is endothermic and requires heat energy (Figure 2). We hypothesize that the resulting $\mathrm{Cu}^{0}$ interacts with hemicellulose in RS, therefore activating the $\mathrm{C}-\mathrm{O}$ bond and promoting its cleavage; this leads to the degradation of hemicellulose into oligosaccharides and monosaccharides [41]. Besides, $\mathrm{Cu}$ also activates the $\mathrm{C}-\mathrm{O}$ bond in cellulose and lignin. Additionally, it is capable of activating the intermolecular hydrogen bonds in cellulose resulting in the production of glucan and cellobiose in the reaction under more severe conditions [42].

Since the RS did not dissolve efficiently in water, the hemicellulose conversion in the RS was not easy. Under the elevated temperature, the hemicellulose conversion in the RS followed the decomposition process of hemicellulose in LHW, which is divided into three steps. First, the catalyst seeps into the RS structure, encountering the low-molecular-weight hemicellulose in the outer region of primary wall $(\mathrm{P})$ and secondary wall(S) layers [12]. It catalyzes the $\mathrm{C}-\mathrm{O}$ bond cleavage generating the primary products on the surface of RS, which sequentially dissolve in the water. A fraction of lignin also dissolves in water, crumbling the rigid structure of RS. Second, the catalyst seeps deep into the inner $S_{2}$ layer, encountering the high-molecular-weight hemicellulose and degrading it as time increases. Third, the catalyst decomposes these products further, converting them into other 
byproducts [43]. The hemicellulose from sweet sorghum bagasse (SSB) consists of arabinoxylan with the branched chain of glucuronic and O-acetyl groups [44]. It decomposed into xylose oligomers, glucuronic acid, and acetic acid. These primary products underwent a second degradation into xylose monomers, furfurals, glycolic acid, and formic acid. The hemicellulose removal was similar to the recently reported results using cold caustic extraction treatment [12]. Simultaneously, the cellulose tethered to hemicellulose and lignin partially converted to polysaccharides or glucose monomer, owing to its regular microcrystalline structure, and the wrapping structure of hemicellulose and lignin, although the majority of hemicellulose was removed. We suppose that if cellulose conversion in RS proceeds successfully, lignin might be removed. However, further research is required to verify this assumption.

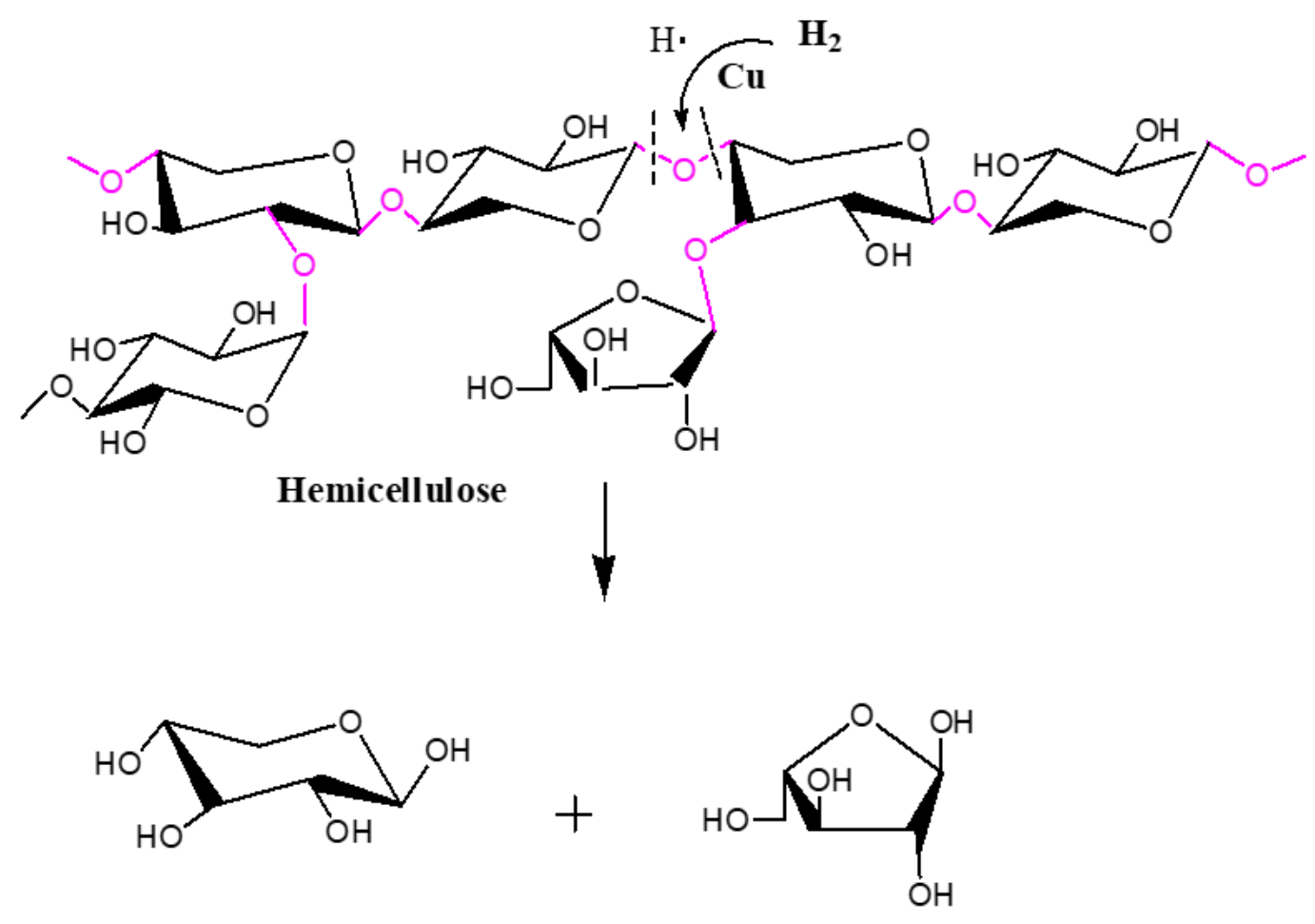

Xylose

Arabinose

Figure 2. Mechanism of hydrogenation of hemicellulose from RS.

\subsection{XRD, XPS, FTIR, and SEM Characterization}

\subsubsection{X-ray Diffraction (XRD) of Catalyst}

$\mathrm{XRD}$ was carried out to test the $\mathrm{CuO}$ catalyst before and after hydrogenolysis. The XRD spectrum reflects the characteristic diffraction peaks of the sample compared with the standards from the Joint Committee on Powder Diffraction Standards (JCPDS) card (Figure 3). The apparent diffraction peaks at $2 \theta=35.5$ and $38.7^{\circ}$ in the $\mathrm{CuO}$ catalyst before hydrogenolysis indicated the presence of $\mathrm{CuO}$ (JCPDS 05-0661), proving that the calcined catalyst was pure $\mathrm{CuO}$ before hydrogenolysis reaction. After the hydrogenolysis, the diffraction peaks of $\mathrm{CuO}$ disappeared, while the peaks at $2 \theta=43.4,50.4$, and $74.1^{\circ}$ assignable to metallic $\mathrm{Cu}^{0}$ (JCPDS04-0836) appeared, proving that the $\mathrm{CuO}$ catalyst was turned into active $\mathrm{Cu}^{0}$ after the hydrogenolysis of RS [45]. 


\subsubsection{X-ray Photoelectron Spectroscopy (XPS) of Catalyst}

As illustrated in Figure 4, XPS was also carried out to gain further insight into the nature composition information of $\mathrm{CuO}$ catalyst before and after hydrogenolysis of RS. We can see from Figure 4, two photoelectron peaks centered at 933.7 and $953.6 \mathrm{eV}$ in Cu2p spectra with two strong satellite peaks at 943.7 and $962.3 \mathrm{eV}$, suggesting that the predominant species was $\mathrm{CuO}$. Moreover, only two peaks at 933.7 and $953.6 \mathrm{eV}$ associated respectively with $\mathrm{Cu} 2 \mathrm{p}_{3 / 2}$ and $\mathrm{Cu} 2 \mathrm{p}_{1 / 2}$ peaks of $\mathrm{Cu}^{0}$ were evident in the catalyst after hydrogenolysis. Additionally, the absence of satellite peaks at 943.7 and $962.3 \mathrm{eV}$ corresponding to the spectra of $\mathrm{Cu}^{2+}$ species in $\mathrm{CuO}$ were noted, indicating that $\mathrm{Cu}^{2+}$ in the $\mathrm{CuO}$ was fully reduced to $\mathrm{Cu}^{0}[46]$. $\mathrm{Cu} 2 \mathrm{p}_{3 / 2}$ peak in $\mathrm{Cu}$ (II) oxide was shifted and broader compared to $\mathrm{Cu}^{0}$ metal. The results conform to the XRD analysis in Figure 3.

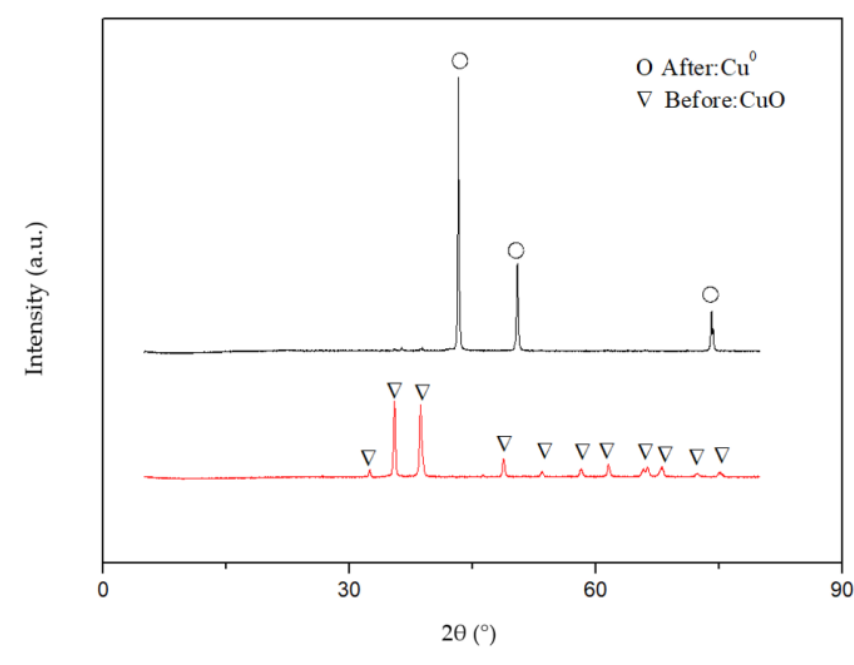

Figure 3. XRD of $\mathrm{CuO}$ before and after hydrogenolysis of RS.

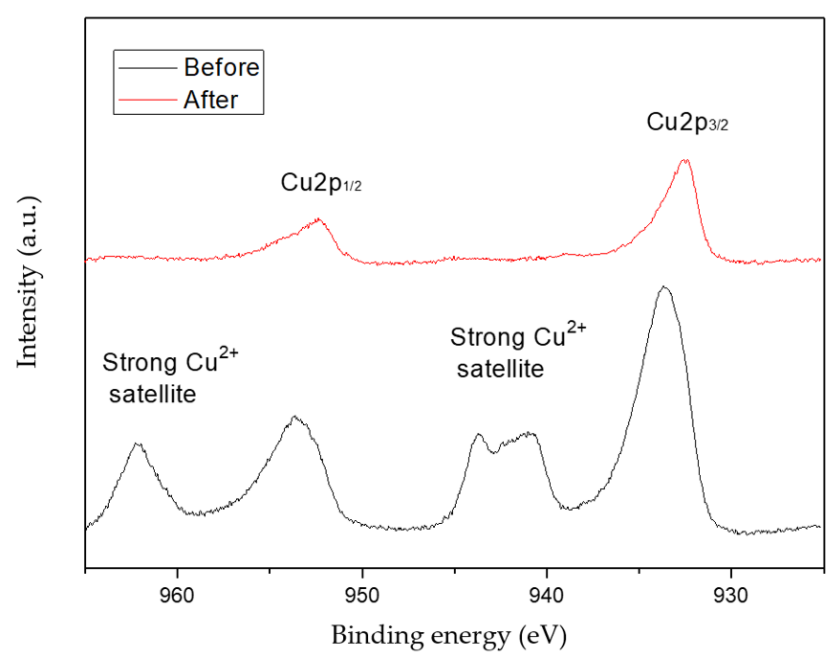

Figure 4. XPS of $\mathrm{CuO}$ before and after hydrogenolysis of RS.

\subsubsection{Scanning Electron Microscopy (SEM) of Solid Residue}

SEM was performed to compare the physical structures of the RS in the solid residues before and after hydrogenolysis samples (Figure 5). The surface of untreated native RS was intact and smooth, covered with a thick layer of wax. It was not conducive to the dissolution of the organic matter of RS and diffusion of the catalysts (Figure 5A). As observed in Figure 5B, after the hydrogenation reaction, the surface severely collapsed, the rigid and ordered fibrils encased in the wax layer 
disintegrated, pores and cracks emerged on the wall surface, and secondary cell walls were exposed [8]. These alterations may be due to the disruption of the structure and reduction in hemicellulose. Morone et al. [47] reported similar changes for other RS treatments.

\subsubsection{Fourier-Transform Infrared Spectroscopy (FTIR) of Solid Residue}

The FTIR spectra were assessed to compare the solid residues before and after hydrogenolysis corresponding to lignin, cellulose, and hemicellulose. The changes in the characteristics were analyzed by the functional groups that served as adsorption sites in the major constituents during the catalytic conversion (Figure 6).
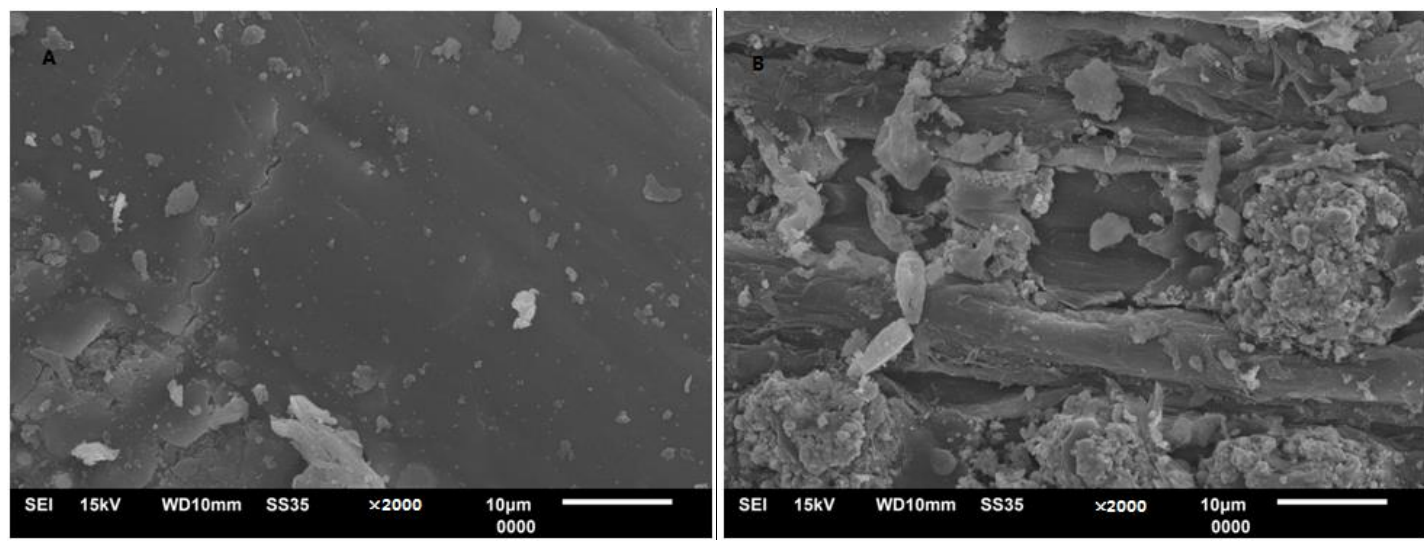

Figure 5. SEM of solid residuebefore and after hydrogenolysis ((A) before; (B) after).
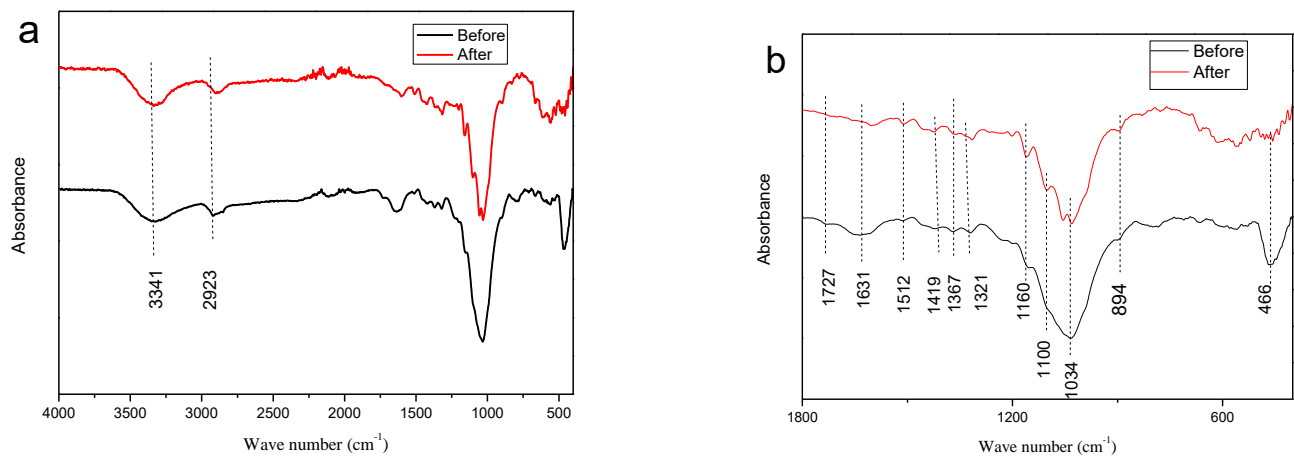

Figure 6. FTIR of solid residue before and after hydrogenolysis $\left((\mathbf{a}): 4000-400 \mathrm{~cm}^{-1},(\mathbf{b}): 1800-400 \mathrm{~cm}^{-1}\right)$.

The infrared spectra revealed numerous adsorption peaks in a wavenumber range $4000-400 \mathrm{~cm}^{-1}$. The band at $3341 \mathrm{~cm}^{-1}$ corresponding to $\mathrm{O}-\mathrm{H}$ stretching represents the vibration of the hydroxyl groups in cellulose and lignin that weakened after catalysis. This suggests the depolymerization of the cellulose and lignin in HRS. The absorption band at $1512 \mathrm{~cm}^{-1}$ represents the characteristic peak of lignin related to the vibration of aromatic rings present in it. The peak at $466 \mathrm{~cm}^{-1}$ reduced sharply after the catalytic reaction, which indicates that the proportion of lignin decreased [48]. The two peaks at $1727 \mathrm{~cm}^{-1}$ and $1367 \mathrm{~cm}^{-1}$ represent the alkyl esters of acetyl groups in hemicellulose. Both these peaks were weaker in the spectrum of HRS, indicating the removal of the linkages between hemicellulose and lignin, which provided additional evidence for the successful conversion of hemicelluloses [49]. The results conform to the data in Table 2. The absorption peaks at $2923 \mathrm{~cm}^{-1}, 1419 \mathrm{~cm}^{-1}$, and $1321 \mathrm{~cm}^{-1}$ corresponding to the $\mathrm{C}-\mathrm{H}$ stretching vibration from the $\mathrm{CH}_{2}$ group represent the $\mathrm{CH}_{2} \mathrm{OH}$ group of $\mathrm{C}_{6}$ in cellulose. The peak at $1631 \mathrm{~cm}^{-1}$ represents the $\mathrm{C}=\mathrm{O}$ group from carboxylic acid with an intermolecular hydrogen bond in RS, and it weakened after the catalytic reaction $[8,50]$. The characteristic band at 
$1034 \mathrm{~cm}^{-1}$ decreased in HRS. It represents the $\mathrm{C}-\mathrm{O}-\mathrm{C}$ ether vibration in cellulose and hemicellulose and the $\mathrm{C}-\mathrm{O}$ stretching in cellulose, hemicellulose, and lignin. The enhancement of $\mathrm{C}-\mathrm{O}-\mathrm{C}$ ring skeletal vibration at $1100 \mathrm{~cm}^{-1}$, the $\mathrm{C}-\mathrm{O}-\mathrm{C}$ glycosidic bond stretching at $1160 \mathrm{~cm}^{-1}$, and $\beta$-glycosidic bond stretching at $894 \mathrm{~cm}^{-1}$ after the catalytic reaction indicate the increase in cellulose content in the HRS solid residue, caused by the removal of hemicellulose [49]. The FTIR spectra showed that rigid network structure of rice straw was abolished after the hydrogenolysis process, and the results were consistent with Figure 5b.

\section{Conclusions}

In this paper, we examined one-step, $\mathrm{CuO}$-catalyzed hemicellulose conversion from raw rice straw, without any pretreatment. The $\mathrm{CuO}$ catalyst selectively activated the $\mathrm{C}-\mathrm{O}$ bond in the major components of rice straw: cellulose, hemicellulose, and lignin. The maximum hemicellulose hydrogenolysis conversion and partial degradation of cellulose and lignin were obtained. SEM and FTIR techniques were employed to verify the removal of hemicellulose and the changes in the structural and chemical properties. Finally, we deduced the mechanism of CuO-catalyzed hydrogenolysis. The selective catalytic conversion of cellulose and hemicellulose in rice straw into sugars under mild conditions provided raw materials for subsequent bulk chemicals, representing an ideal route for the utilization of this abundant resource.

Author Contributions: J.Z. (Jianliang Zhu) conceived and designed the experiments; X.Y. performed the experiments, analyzed the data, and composed the manuscript; J.Z. (Jing Zhao) performed the XRD and XPS experiments and data analysis; J.L. checked and edited the manuscript. All authors have read and agreed to the published version of the manuscript.

Funding: This work was financially supported by the National Natural Science Foundation of China (21808108), the Natural Science Foundation of Jiangsu Province (BK20180702), the Natural Science Foundation of the Jiangsu Higher Education Institutions of China (18KJB610007), and the Jiangsu postdoctoral research funding program (2019K242).

Conflicts of Interest: The authors declare no conflict of interest.

\section{References}

1. Peng, P.; She, D. Isolation, structural characterization, and potential applications of hemicelluloses from bamboo: A review. Carbohydr. Polym. 2014, 112, 701-720. [CrossRef]

2. Chen, H.Y.; Liu, J.B.; Chang, X.; Chen, D.M.; Xue, Y.; Liu, P.; Lin, H.L.; Han, S. A review on the pretreatment of lignocellulose for high-value chemicals. Fuel Process. Technol. 2017, 160, 196-206. [CrossRef]

3. Liguori, R.; Faraco, V. Biological processes for advancing lignocellulosic waste biorefinery by advocating circular economy. Bioresour. Technol. 2016, 215, 13-20. [CrossRef] [PubMed]

4. Morone, A.; Sharma, G.; Sharma, A.; Chakrabarti, T.; Pandey, R.A. Evaluation, applicability and optimization of advanced oxidation process for pretreatment of rice straw and its effect on cellulose digestibility. Renew. Energy 2018, 120, 88-97. [CrossRef]

5. Zhang, Y.L.; Chen, X.H.; Yu, G.; Zhou, X.F. A physicochemical method for increasing methane production from ricestraw: Extrusion combined with alkali pretreatment. Appl. Energy 2015, 160, 39-48. [CrossRef]

6. Pan, M.Z.; Gan, X.H.; Mei, C.T.; Liang, Y.F. Structural analysis and transformation of biosilica during lignocellulose fractionation of rice straw. J. Mol. Struct. 2017, 1127, 575-582. [CrossRef]

7. Amiri, H.; Karimi, K.; Zilouei, H. Organosolv pretreatment of rice straw for efficient acetone, butanol, and ethanol production. Bioresour. Technol. 2014, 152, 450-456. [CrossRef] [PubMed]

8. Castoldi, R.; Correa, G.V.; Morais, G.R.; Souza, C.G.M.; Bracht, A.; Peralta, R.A.; Moreira, R.F.P.M.; Peralta, R.M. Liquid nitrogen pretreatment of eucalyptus sawdust and rice hull for enhanced enzymatic saccharification. Bioresour. Technol. 2017, 224, 648-655. [CrossRef] [PubMed]

9. Karimia, K.; Kheradmandinia, S.; Taherzadeh, M.J. Conversion of rice straw to sugars by dilute-acid hydrolysis. Biomass Bioener. 2006, 30, 247-253. [CrossRef] 
10. Zhao, L.F.; Yuan, Z.Y.; Kapu, N.S.; Chang, X.F.; Beatson, R.; Trajanno, H.L.; Martinez, D.M. Increasing efficiency of enzymatic hemicellulose removal from bamboo for production of high-grade dissolving pulp. Bioresour. Technol. 2017, 223, 40-46. [CrossRef] [PubMed]

11. Syaftika, N.; Matsumura, Y. Comparative study of hydrothermal pretreatment for rice straw and its corresponding mixture of cellulose, xylan, and lignin. Bioresour. Technol. 2018, 255, 1-6. [CrossRef] [PubMed]

12. Li, J.G.; Hu, H.C.; Li, H.L.; Huang, L.L.; Chen, L.H.; Ni, Y.H. Kinetics and mechanism of hemicelluloses removal from cellulosic fibers during the cold caustic extraction process. Bioresour. Technol. 2017, 234, 61-66. [CrossRef] [PubMed]

13. Li, T.; Remón, J.; Shuttleworth, P.S.; Jiang, Z.; Fan, J.; Clark, J.H.; Budarin, V.L. Controllable production of liquid and solid biofuels by doping-free, microwave-assisted, pressurised pyrolysis of hemicellulose. Energy Convers. Manag. 2017, 144, 104-113. [CrossRef]

14. Zhao, X.H.; Tong, T.T.; Li, H.L.; Lu, H.J.; Ren, J.L.; Zhang, A.P.; Deng, X.M.; Chen, X.Y.; $\mathrm{Wu}$, A.M. Characterization of hemicelluloses from Neolamarckiacadamba (Rubiaceae) during xylogenesis. Carbohydr. Polym. 2017, 156, 333-339. [CrossRef]

15. Ren, Y.L.; Wang, J.J.; Liu, Z.; Ren, Y.L.; Li, G.Z. Hydrogen production from the monomeric sugars hydrolyzed from hemicellulose by Enterobacter aerogenes. Renew. Energy 2009, 34, 2774-2779. [CrossRef]

16. Zhang, J.; Wang, Y.H.; Qu, Y.S.; Wei, Q.Y.; Li, H.Q. Effect of the organizational difference of corn stalk on hemicelluloses extraction and enzymatic hydrolysis. Ind. Crop. Prod. 2018, 12, 698-704. [CrossRef]

17. Elumalai, S.; Agarwal, B.; Sangwan, R.S. Thermo-chemical pretreatment of rice straw for further processing for levulinic acid production. Bioresour. Technol. 2016, 218, 232-246. [CrossRef]

18. Liu, Z.; Li, L.F.; Liu, C.; Xu, A.R. Saccharification of cellulose in the ionic liquids and glucose recovery. Renew. Energy 2017, 106, 99-102. [CrossRef]

19. Chareonlimkun, A.; Champreda, V.; Shotipruk, A.; Laosiripojana, N. Reactions of $C_{5}$ and $C_{6}$-sugars, cellulose, and lignocellulose under hot compressed water $(\mathrm{HCW})$ in the presence of heterogeneous acid catalysts. Fuel 2010, 89, 2873-2880. [CrossRef]

20. Dai, Y.Z.; Si, M.Y.; Chen, Y.H.; Zhang, N.L.; Zhou, M.; Liao, Q.; Shi, D.Q.; Liu, Y.N. Combination of biological pretreatment with $\mathrm{NaOH} / \mathrm{Urea}$ pretreatment at cold temperature to enhance enzymatic hydrolysis of rice straw. Bioresour. Technol. 2015, 198, 725-731. [CrossRef]

21. Pedersen, M.; Meyer, A.S. Influence of substrate particle size and wet oxidation on physical surface structures and enzymatic hydrolysis of wheat straw. J. Biotechnol. Prog. 2009, 25, 399-408. [CrossRef] [PubMed]

22. Hurona, M.; Hudebinea, D.; Ferreira, N.L.; Lachenal, D. Impact of delignification on the morphology and the reactivity of steam exploded wheat straw. Ind. Crop. Prod. 2016, 79, 104-109. [CrossRef]

23. Wu, Y.H.; Gu, F.N.; Xu, G.W.; Zhong, Z.Y.; Su, F.B. Hydrogenolysis of cellulose to $\mathrm{C}_{4}-\mathrm{C}_{7}$ alcohols over bi-functiona $\mathrm{CuO}-\mathrm{MO} / \mathrm{Al}_{2} \mathrm{O}_{3}\left(\mathrm{M}^{\circ}=\mathrm{Ce}, \mathrm{Mg}, \mathrm{Mn}, \mathrm{Ni}, \mathrm{Zn}\right)$ catalysts coupled with methanol reforming reaction. Bioresour. Technol. 2013, 137, 311-317. [CrossRef] [PubMed]

24. Zhong, C.; Wang, C.M.; Huang, F.; Wang, F.X.; Jia, H.H.; Zhou, H.; Wei, P. Selective hydrolysis of hemicellulose from wheat straw by a nanoscale solid acid catalyst. Carbohydr. Polym. 2015, 131, 384-391. [CrossRef]

25. Huang, Y.B.; Fu, Y. Hydrolysis of cellulose to glucose by solid acid catalysts. Green Chem. 2013, 15, 1095-1111. [CrossRef]

26. Si, W.Q.; Li, Y.C.; Zheng, J.; Wei, S.A.; Wang, D. Enhanced hydrolysis of bamboo biomass by chitosan based solid acid catalyst with surfactant addition in ionic liquid. Carbohydr. Polym. 2017, 174, 154-159. [CrossRef]

27. Zhang, X.J.; Zhao, T.S.; Hara, N.; Jin, Y.Z.; Zeng, C.Y.; Yoneyama, Y.; Tsubaki, N. Direct conversion of rice straw catalyzed by solid acid supported-Pt catalyst using in situ $\mathrm{H}_{2}$ by ethanol steam reforming. Fuel 2014, 116, 34-38. [CrossRef]

28. Li, S.H.; Gu, Z.G.; Bjornson, B.E.; Muthukumarappan, A. Biochar based solid acid catalyst hydrolyze biomass. J. Environ. Chem. Eng. 2013, 1, 1174-1181. [CrossRef]

29. Sinağ, A.; Yumak, T.; Balci, V.; Kruse, A. Catalytic hydrothermal conversion of cellulose over $\mathrm{SnO}_{2}$ and $\mathrm{ZnO}$ nanoparitcle catalysts. J. Supercrit. Fluid. 2011, 56, 179-185. [CrossRef]

30. Cao, X.F.; Peng, X.W.; Sun, S.N.; Zhong, L.X.; Chen, W.; Wang, S. Hydrothermal conversion of xylose, glucose, and cellulose under the catalysis of transition mental sulfates. Carbohydr. Polym. 2015, 118, 44-51. [CrossRef]

31. Tathod, A.P.; Dhepe, P.L. Efficient method for the conversion of agricultural waste into sugar alcohols over supported bimetallic catalysts. Bioresour. Technol. 2015, 178, 36-44. [CrossRef] [PubMed] 
32. Liu, C.W.; Zhang, Z.N.; Zhai, X.F.; Wang, X.Z.; Gui, J.Z.; Zhang, C.H.; Zhu, Y.L.; Li, Y.W. Synergistic effect between copper and different meal oxides in the selective hydrogenolysis of glucose. New J. Chem. 2019, 43, 3733-3740. [CrossRef]

33. Negoi, A.; Triantafyllidis, K.; Parvulescu, V.I.; Coman, S.M. The hydrolytic hydrogenation of cellulose to sorbitol over M (Ru, Ir, Pd, Rh)-BEA-zeolite catalysts. Catal. Today 2014, 223, 122-128. [CrossRef]

34. Sluiter, A.; Hames, B.; Ruiz, R.; Scarlata, C.; Sluiter, J.; Templeton, D.; Crocker, D. Determination of structural carbohydrates and lignin in biomass. Lab. Anal. Proced. 2008, 1671, 1-16.

35. Kassaye, S.; Pant, K.K.; Jain, S. Hydrolysis of cellulosic bamboo biomass into reducing sugars via a combined alkaline solution and ionic liquid pretreatment steps. Renew. Energy 2017, 104, 177-184. [CrossRef]

36. Imman, S.; Arnthong, J.; Burapatana, V.; Champreda, V.; Laosiripojana, N. Influence of alkaline catalyst addition on compressed liquid hot water pretreatment of rice straw. Chem. Eng. J. 2015, 278, 85-91. [CrossRef]

37. Hou, X.D.; Feng, G.J.; Mei, Y.; Huang, C.M.; Zhang, Y. Significantly enhanced enzymatic hydrolysis of rice straw via a highperformance two-stage deep eutectic solvents synergistic pretreatment. Bioresour. Technol. 2017, 238, 139-146. [CrossRef]

38. Kapoor, M.; Soam, S.; Agrawal, R.; Gupta, R.P.; Tuli, D.K.; Kumar, R. Pilot scale dilute acid pretreatment of rice straw and fermentable sugar recovery at high solid loadings. Bioresour. Technol. 2017, 224, 688-693. [CrossRef]

39. Li, J.; Zhang, M.; Li, J.; Wang, D.H. Corn stover pretreatment by metal oxides for improving lignin removal and reducing sugar degradation and water usage. Bioresour. Technol. 2018, 263, 232-241. [CrossRef]

40. Pang, F.; Xue, S.L.; Yu, S.S.; Zhang, C.; Li, B.; Kang, Y. Effects of microwave powder and microwave irradiation time on pretreatment efficiency and characteristics of corn stover using combination of steam explosion and microwave irradiation (SE-MI) pretreatment. Bioresour. Technol. 2012, 118, 111-119. [CrossRef]

41. Deng, W.P.; Zhang, H.X.; Xue, L.Q.; Zhang, Q.Z.; Wang, Y. Selective activation of the C-O bonds in lignocellulosic biomass for the efficient production of chemicals. Chin. J. Catal. 2015, 36, 1440-1460. [CrossRef]

42. Deng, W.P.; Zhang, Q.H.; Wang, Y. Catalytic transformation of cellulose and its derived carbohydrates into chemicals involving C-C bond cleavage. J. Energy Chem. 2015, 24, 595-607. [CrossRef]

43. Sukma, L.P.P.; Wang, X.H.; Li, S.; Nguyen, T.T.; Pu, J.L.; Qian, E.W. Two-step saccharification of rice straw using solid acid catalysts. Ind. Eng. Chem. Res. 2019, 58, 5686-5697. [CrossRef]

44. Yu, Q.; Zhuang, X.S.; Yuan, Z.H.; Wang, W.; Qi, W.; Wang, Q.; Tan, X.S. Hydrolysis of sweet sorghum bagasse hemicelluloses with liquid hot water and its mechanism. CIESC J. 2012, 2, 559-605.

45. Liu, H.L.; Huang, Z.W.; Kang, H.X.; Li, X.M.; Xia, C.G.; Chen, J.; Liu, H.C. Efficient bimetallic NiCu-SiO 2 catalysts for selective hydrogenolysis of xylitol ethylene glycol and propylene glycol. App. Catal. B Environ. 2018, 220, 251-263. [CrossRef]

46. Cai, F.F.; Pan, D.H.; Ibrahim, J.J.; Zhang, J.; Xiao, G.M. Hydrogenolysis of glycerol over supported bimetallic $\mathrm{Ni} / \mathrm{Cu}$ catalysts with and without external hydrogen addition in a fixed-bed flow reactor. Appl. Catal. A Gen. 2018, 564, 172-182. [CrossRef]

47. Morone, A.; Pandey, R.A.; Chakrabarti, T. Evaluation of organocat process as a pretreatment during bioconversion of rice straw. Ind. Crop. Prod. 2017, 99, 7-18. [CrossRef]

48. Lü, J.L.; Zhou, P.J. Optimization of microwave-assisted $\mathrm{FeCl}_{3}$ pretreatment conditions of rice straw and utilization of Trichodermaviride and Bacillus pumilus for production of reducing sugars. Bioresour. Technol. 2011, 13, 6966-6971. [CrossRef]

49. Binod, P.; Satyanagalakshmi, K.; Sindhu, R.; Janu, K.U.; Sukumaran, R.K.; Pandey, A. Short duration microwave assisted pretreatment enhances the enzymatic saccharification and fermentable sugar yield from sugarcane bagasse. Renew. Energy 2012, 37, 109-116. [CrossRef]

50. Kim, I.; Saif, U.R.M.; Han, J.I. Fermentable sugar recovery and adsorption potential of enzymatically hydrolyzed rice straw. Bioresour. Technol. 2014, 66, 555-561. [CrossRef]

Publisher's Note: MDPI stays neutral with regard to jurisdictional claims in published maps and institutional affiliations. 